\title{
PRESENÇA DE FUNGOS COM POTENCIAL PATOGÊNICO EM INSTRUMENTOS DE TOSA
}

\author{
Antonella Souza Mattei ${ }^{1}$, Isabel Martins Madrid², Rosema Santin ${ }^{3}$, Luiz Filipe Damé \\ Schuch $^{4}$, Mário Carlos Araújo Meireles ${ }^{4}$
}

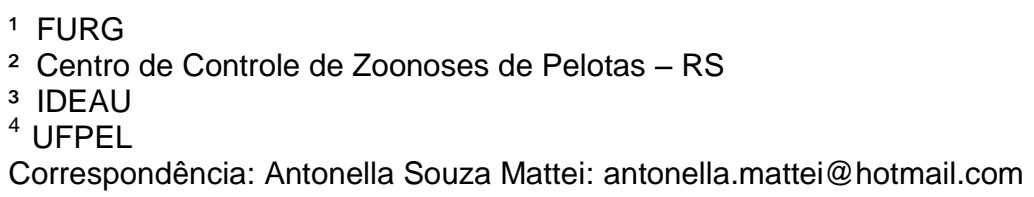

RESUMO: As dermatopatias correspondem a maioria dos atendimentos realizados em clínicas veterinárias de pequenos animais. Dentre essas, as micoses cutâneas comumente diagnosticadas são dermatofitose, malasseziose e candidose. Além disso, os cuidados com animais de estimação cresceram auxiliados pelo surgimento de pet shops. O objetivo foi isolar e identificar leveduras e dermatófitos em instrumentos de tosa de ambientes veterinários em Pelotas, RS, Brasil. Em pet shops, consultórios e clínicas veterinárias foram coletadas amostras de rascadeiras e lâminas da máquina através de swabs estéreis e impressão em placas com ágar Sabouraud acrescido de cloranfenicol, azeite de oliva e ciclohexemida, incubadas a $25^{\circ}$ e $37^{\circ} \mathrm{C}$, por até 35 dias. As colônias filamentosas foram identificadas conforme as características do grupo dermatófitos e as leveduras, através de método automatizado. A análise de frequência de isolamento foi realizada pelo método qui-quadrado. Foram coletados 1 hospital veterinário, 4 clínicas, 4 consultórios veterinários e 6 pet shops resultando em 150 amostras, sendo 80 da lâmina da máquina de tosa e 70 da rascadeira. 0 isolamento fúngico foi obtido em 58 amostras, das quais $58,6 \%$ eram da lâmina da máquina de tosa e $41,4 \%$ da rascadeira, resultando em 78 isolados leveduriformes; uma vez que não foram isolados fungos filamentosos do grupo dermatófitos. Malassezia pachydermatis foi a levedura mais frequentemente isolada, tanto nas amostras da lâmina da máquina de tosa quanto nas da rascadeira, enquanto que, Trichosporon sp. foi isolado somente nas da rascadeira. Assim, a lâmina da máquina de tosa foi a mais contaminada, com predominância de M. pachydermatis, entretanto, nenhum dermatófito foi isolado.

Palavras-chave: pet shops; lâmina; rascadeira; banho

\section{OCCURRENCE OF FUNGI WITH PATHOGENIC POTENTIAL IN SHEARING TOOLS}

\begin{abstract}
Dermatopathies account for most visits to small animal veterinary clinics. Among these, the most commonly diagnosed cutaneous mycoses are dermatophytosis, malasseziosis and candidiasis. Due to the importance of the growing pet care business with the spread of pet shops, this study aimed to isolate and identify the occurrence of yeasts and dermatophytes in shearing tools used in veterinary environments in the city of Pelotas, State of Rio Grande do Sul, Brazil. Slicker and clipper blade samples were collected in pet shops as well as veterinary offices and clinics by sterile swabs and pressed onto plates containing Sabouraud agar added with chloramphenicol, olive oil and cycloheximide, incubated at $25^{\circ}$ and $37^{\circ} \mathrm{C}$ for up to 35 days. Filamentous colonies were identified according to dermatophytes group characteristics, and yeasts according to the automated method. Frequency of isolation analysis was performed by the chi-square method. Samples were collected at one veterinary hospital, four clinics, four veterinary offices and six pet shops, totaling 150 samples, 80 of which from clipper blades and 70 from slickers. Fungal isolation was positive in 58 samples, $58.6 \%$ of which from clippers and $41.4 \%$ from slickers, resulting in 78 yeast isolates; filamentous fungi from the dermatophytes group were not found. Yeasts of the Candida, Malassezia, Trichosporon and Rhodotorula genus were identified. The Malassezia pachydermatis was the most frequent isolated, both from clipper blade and slicker samples, whereas the Trichorospon genus was only isolated from slicker samples. Thus, the clipper blade presented the highest contamination, with Malassezia pachydermatis predominance; however, no dermatophyte was found.
\end{abstract}

Key Words: pet shops; blade; slicker; bath 


\section{INTRODUÇÃO}

A população de animais de companhia, nos últimos anos, tem aumentado significativamente, estando esses cada vez mais inseridos no cotidiano. Seguindo esta tendência mundial, estima-se que a população de animais de estimação seja de 82 milhões. Desse modo, os cuidados com animais de estimação dispensados pelos proprietários cresceram auxiliados pelo surgimento de pet shops (Chao, 2011).

A maioria dos atendimentos realizados em clínicas veterinárias corresponde às dermatopatias, sendo as micoses consideradas a terceira causa mais comum de infecções cutâneas em animais de estimação. Assim, as micoses cutâneas comumente diagnosticadas são dermatofitose, malasseziose e candidose (Machado et al., 2004).

A dermatofitose é causada por um grupo de fungos queratinofílicos transmitidos através do contato direto com lesões, entre e intra-espécies ou pelo contato indireto, através de instrumentos compartilhados e ambientes contaminados (Machado et al., 2004; Ates et al., 2008; Madrid et al., 2012). O grande poder de contágio entre os animais, alto custo do tratamento, dificuldade de medidas de controle e os efeitos em saúde pública dessa micose, podem explicar a sua grande importância (Chermette et al., 2008).

Desse modo, a limpeza e desinfecção de superfícies são recomendadas para controlar a propagação de patógenos em ambientes, removendo mecanicamente sujidades que predispõem 0 crescimento de microrganismos e eliminando a microbiota presente (Andersen et al., 2009). Nesse sentido, o objetivo desse trabalho foi isolar e identificar leveduras e dermatófitos em instrumentos de tosa de ambientes veterinários.

\section{MATERIAL E MÉTODOS}

Os locais de estudo foram selecionados com base na utilização rotineira da lâmina de tosa e rascadeira, sendo a coleta realizada em pet shops, hospital, clínicas e consultórios veterinários da cidade de Pelotas, Rio Grande do Sul, Brasil.

As coletas foram realizadas ao final do expediente de cada local, sem prévia limpeza dos instrumentos.

Para obtenção das amostras, as rascadeiras foram pressionadas sobre meios de cultivos, enquanto que, as crostas e pelos presentes nas lâminas das máquinas de tosa foram colhidas com auxílio de swabs estéreis. Todas as amostras foram semeadas em duplicata, em ágar Sabouraud acrescido de cloranfenicol (Neogen Acumedia, Michigan/EUA) e azeite de oliva e ágar Sabouraud acrescido de cloranfenicol e cicloheximida (BD, Nova Jersey/EUA), sendo incubadas a $25^{\circ} \mathrm{C}$ por até 35 dias e a $37^{\circ} \mathrm{C}$ por cinco dias, de acordo com Zaitz et al.(2004).

As colônias filamentosas obtidas do cultivo das amostras dos instrumentos de tosa foram identificadas de acordo com a macroscopia e microscopia de fungos do grupo dermatófitos. Quando a identificação das espécies fúngicas, através da macro e micromorfologia das colônias, não era possível, realizou-se microcultivo entre lâminas para observação de estruturas completas de frutificação e ornamentação desses fungos (Riddell, 1950).

As leveduras foram identificadas quanto às características do verso e reverso das colônias, bordas, consistência, coloração e textura. Para avaliação dos aspectos micromorfológicos foi realizado exame direto através de esfregaço dos cultivos 
corado pelo método de Gram, com posterior visualização em aumento de 1000X em óleo de imersão. Como testes complementares para identificação de gênero e espécie foram utilizados a prova da catalase e urease, prova do tubo germinativo e ágar CHROMagar $^{\circledR}$ Candida (DIFCO, Meylan Cedex/França) (Zaitz et al., 2004). Para a confirmação das espécies foi utilizado o kit comercial de identificação automatizada (ID 32C, BioMérieux SA, Marcy l'Etoile/França).

$A$ análise de frequência de isolamento foi realizada pelo método qui-quadrado, através do Epi info 6 (Yurayart et al., 2011).

\section{RESULTADOS}

As amostras foram coletadas de um hospital veterinário, quatro clínicas, quatro consultórios veterinários e seis pet shops, nos quais foram realizadas dez coletas (metade do período para pesquisa de leveduras e o restante, pesquisa de dermatófitos) em cada local de estudo, resultando em 150 amostras para a pesquisa fúngica, sendo, 80 provenientes de lâmina da máquina de tosa e 70 de rascadeira.

$\mathrm{O}$ isolamento fúngico foi obtido em $58(n=150)$ amostras, das quais $58,6 \%$ (34/58) referiam-se a lâmina da máquina de tosa e $41,4 \%(24 / 58)$ da rascadeira, o que resultou em 78 isolados leveduriformes; uma vez que não foram isolados fungos filamentosos pertencentes ao grupo de dermatófitos (Tab. 1).

\begin{tabular}{|c|c|c|c|}
\hline $\begin{array}{l}\text { LOCAIS DE } \\
\text { COLETA }\end{array}$ & $\begin{array}{l}\text { LÄMINA } \\
(\mathrm{n}=\mathbf{8 0})\end{array}$ & $\begin{array}{l}\text { RASCADEIRA } \\
(\mathrm{n}=70)\end{array}$ & TOTAL \\
\hline Hospital $(n=10)$ & $7^{2}$ & - & 7 \\
\hline Clínicas $(n=40)$ & $5^{\circ}$ & $9^{2}$ & 14 \\
\hline Consultórios $(n=40)$ & $9^{\circ}$ & $7^{2}$ & 16 \\
\hline Pet Shops $(n=60)$ & $13^{\circ}$ & $8^{2}$ & 21 \\
\hline TOTAL & $\begin{array}{c}34 \\
(p=0,002)\end{array}$ & $\begin{array}{c}24 \\
(p=0,49)\end{array}$ & 58 \\
\hline
\end{tabular}

$a, b, c-$ letras iguais na coluna não apresentam diferença estat stica ente as médias, através do método qui-quadrado.
Dos 78 isolados fúngicos obtidos, 27 pertenciam ao gênero Candida, 37 ao gênero Malassezia, dois ao gênero Trichosporon e 12 ao gênero Rhodotorula. Quanto ao local de estudo, obteve-se 0 isolamento das leveduras do gênero Candida e Malassezia em todos os locais, enquanto que o gênero Trichosporon foi isolado somente nas amostras provenientes de clínica veterinária e o gênero Rhodotorula em pet shops e consultórios veterinários.

Quando considerado o instrumento de tosa, o gênero Malassezia foi o mais frequentemente isolado, tanto nas amostras da lâmina da máquina de tosa quanto nas amostras da rascadeira, enquanto que, o gênero Trichosporon foi isolado somente nas amostras da rascadeira (Fig. 1).

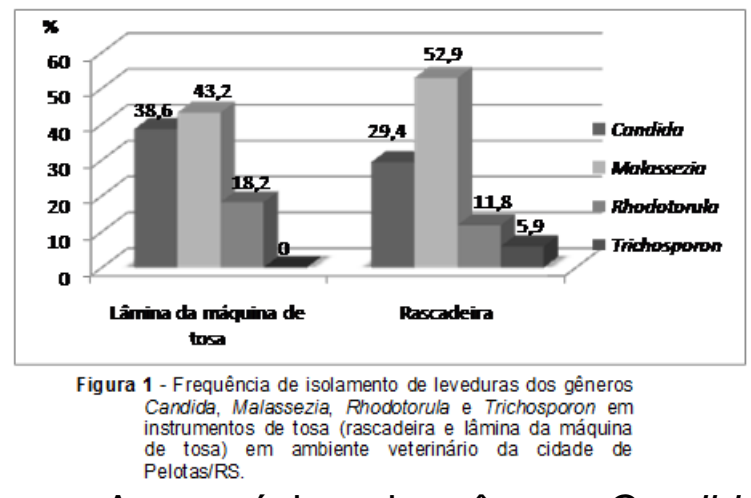

As espécies do gênero Candida foram identificadas como C. parapsilosis (5), C. lipolytica (1), C. catenulata (2), C. guilliermondii (5), C. famata (1) e Candida spp. (13). Enquanto que, no gênero Trichosporon foi identificada apenas a espécie $T$. asahii (2), assim como no gênero Malassezia que foi $M$. pachydermatis (37).

\section{DISCUSSÃO}

Estudos sobre a presença de leveduras e dermatófitos em instrumentos de tosa em ambientes veterinários não foram encontrados na literatura consultada, sendo o presente estudo, o pioneiro. 
No presente estudo, nenhum dermatófito foi isolado nos ambientes pesquisados, demonstrando a baixa frequência desses fungos em instrumentos de tosa e consequentemente, contágio mínimo entre os animais (Ates et al., 2008). A espécie felina pode comportar-se como portadora assintomática de espécies fúngicas zoofílicas, apresentando índices de 8 até $88 \%$ dos casos. Isso ocorre devido à presença de um emulsificado lipídico na superfície da pele que inibe a patogenicidade determinada pelos dermatófitos (Nobre et al., 2000). Além disso, os artroconídios dos dermatófitos ficam viáveis por vários anos no ambiente, assim a transmissão pode ocorrer através de fômites contaminados, como lâminas da máquina de tosa e rascadeira (Dahdah e Scher, 2008; Madrid et al., 2012).

Em relação às leveduras encontradas no presente estudo, Trichosporon asahii foi isolado apenas nas clínicas veterinárias, sendo que sua presença já foi descrita no lavado broncoalveolar e meato acústico externo de pequenos animais sadios (Amaral et al., 1998; Melchert et al., 2008) e como agente causador de granuloma nasal, cistite (gatos), dermatites (cavalos e macacos) e mastite (vacas) (Gartrell et al., 2005). Em humanos, esse gênero é relatado como a segunda causa mais comum de infecções por leveduras após o gênero Candida, em pacientes com doenças hematológicas malignas (Kremery et al., 1999).

O gênero Rhodotorula foi isolado tanto na lâmina da máquina de tosa, quanto na rascadeira de pet shops e consultório veterinário. Anteriormente, era considerado saprófita e contaminante comum de amostras, porém, nos últimos anos tem emergido como patógeno oportunista, particularmente em pacientes imunocomprometidos. Casos de fungemia, endocardites, peritonites e meningites foram associados à infecção deste por cateteres, através do ambiente ou pela microbiota humana (Gomez-Lopez et al., 2005). Casos de infecção sistêmica foram descritos em 43 pacientes entre 1960 a 2000 (Zaas et al., 2003), destacando a importância desse gênero em ambiente hospitalar humano e em veterinária, no qual também há pacientes em estado crítico e debilitados.

Em animais, a levedura mais estudada é Malassezia pachydermatis, considerada parte da microbiota de vários sítios anatômicos em cães e gatos, principalmente do meato acústico externo e tegumento cutâneo (Larsson et al., 1988). Desse modo, a alta frequência de isolamento nos instrumentos de tosa poderia ser explicada, além do fato de ser formadora de biofilme, dificultando sua eliminação de superfícies (Nakagaki et al., 2000). Nos últimos anos, diversos estudos a relacionaram como causadora de dermatite em cães (Larsson et al., 1988; Yurayart et al., 2011), leão marinho (Nakagaki et. al, 2000) e golfinhos (Pollock et al., 2000), reforçando a ideia de que a limpeza e desinfecção do ambiente e fômites são necessárias.

No presente estudo foram isoladas as espécies Candida catenulata, $C$. guilliermondii, C. famata, C. parapsilosis e C. lipolytica, as quais ainda não haviam sido isoladas em ambiente veterinário, sendo este o primeiro relato. Embora essas espécies não estejam frequentemente relacionadas à doenças em animais, são consideradas patogênicas e com crescentes casos descritos na literatura médica (Shin et al., 2000; Pasqualotto et al., 2006). Assim, as espécies $C$. parapsilosis e $C$. guilliermondii já foram descritas como agentes causadores de candidemias e candidose mucocutânea (Boff et al., 2008; Yurayart et al., 2011). Yurayart et 
al. (2011) relataram a associação entre M. pachydermatis e C. parapsilosis como causadores de dermatites seborreicas em cães, destacando que esta última pode ser também ser a causa infecções da pele. Já $C$. lipolytica é raramente associada a infecções em humanos, porém no ano de 2000 foram descritos cinco casos de candidemia em uma unidade pediátrica (Shin et al., 2000). Em veterinária, as espécies $C$. catenulata, $C$. guilliermondii e $C$. famata foram isoladas de vacas com mastite no Brasil, Japão, Polônia e Itália (Moretti et al., 1998; Spanamberg et al., 2008). Em cães hígidos, C. parapsilosis foi isolada em amostras de mucosas vaginal, oral, perianal e prepucial (Cleff et al., 2005; Brito et al., 2009). A candidose em animais está relacionada à $C$. albicans, com relatos em cães, gatos e macacoprego (Ferreiro et al., 2002; Cleff et al., 2008; Ong et al., 2010). No entanto, no presente estudo esta espécie não foi encontrada.

O isolamento dessas leveduras é importante e alerta para a presença em ambiente veterinário, pois são microorganismos com potencial patogênico tanto para animais quanto para humanos, podendo atuar como fator agravante na ocorrência de doenças, alterando a microbiota normal e/ou ainda, desencadear infecções secundárias em animais internados nesses locais (Prado et al., 2008).

\section{CONCLUSÃO}

Os resultados obtidos no presente estudo demonstraram a presença de leveduras nos instrumentos de tosa e ausência de dermatófitos. Assim, a lâmina da máquina de tosa foi a mais contaminada, com predominância de Malassezia pachydermatis, além do isolamento de Candida parapsilosis, C. lipolytica, C. catenulata, C. guilliermondii, C. famata, Rhodotorula spp. e Trichosporon asahii.

\section{AGRADECIMENTOS}

Agradecimentos ao Dr. Luiz Carlos Severo pelo auxílio na pesquisa, ao Conselho Nacional de Desenvolvimento Tecnológico (CNPq), a Coordenação de Aperfeiçoamento de Pessoal de Nível Superior (CAPES) e a Fundação de Amparo à Pesquisa do Estado do Rio Grande do Sul (FAPERGS) pelo suporte financeiro.

\section{REFERÊNCIAS}

AMARAL, R.; IBAÑEZ, J.; MAMIZUKA, E. et al. Microbiota indígena do meato acústico externo de gatos hígidos. Ciência Rural, v.28, n.3, p.441-445, 1998.

ANDERSEN, B.; RASCH, M.; KVIST, J. et al. Floor cleaning: effect on bacteria and organic materials in hospital rooms. Journal of Hospital Infection, v.71, n.1, p.57-65, 2009.

ATES, A.; ILKIT, M.; OZDEMIR, R. et al.. Dermatophytes isolated from asymptomatic dogs in Adana, Turkey: A preliminary study. Journal de Mycologie Médicale, v.18, p.154-157, 2008.

BOFF, E.; LOPES, P.; SPADER, T. et al. Reavaliação da suscetibilidade de Candida à anfotericina B: estudo comparativo com isolados de três hospitais do Estado do Rio Grande do Sul. Revista da Sociedade Brasileira de Medicina Tropical, v.41, n.1, p.36-40, 2008.

BRITO, E.; FONTENELLE, R.; BRILHANTE, R. et al. The anatomical distribution and antimicrobial susceptibility of yeast species isolated from healthy dogs. The Veterinary Journal, v.182, p.320-326, 2009.

CHAO, M. L. Animais de adoração. Revista Planeta. Edição 465, junho, 2011. Disponível em: <http://www. terra.com.br/revistaplaneta /edicoes/465/artigo221057-1.htm>. Acessado em: 7 jul. 2012.

CHERMETTE, R.; FERREIRO, L.; GUILLOT, J. Dermatophytoses in Animals. Mycopathologia, v.166, n.5-6, p.385-405, 2008.

CLEFF, M.; LIMA, A.; FARIA, R. et al. Isolation of Candida spp from vaginal microbiota of health canine females during estrous cycle. Brazilian Journal of Microbiology, v.36, n.2, p.201-204, 2005.

CLEFF, M.; SOARES, M.; MADRID, I. et al. Candidíase cutânea em Cebus apella (macaco 
prego). Ciência Animal Brasileira, v.9, n.3, p.791-795, 2008.

DAHDAH, M.; SCHER, R. Dermatophytes. Current Fungal Infection Reports, v.2, n.2, p.81-86, 2008.

FERREIRO, L.; MOREIRA JR., J.P.R.; APPELT, C.E. et al. Associações entre o isolamento da Candida albicans com a infecção pelo vírus da leucemia felina (FeLV), tratamentos com corticóides ou antimicrobianos em gatos. Acta Scientiae Veterinariae, v.30, n.3, p.179-183, 2002.

GARTRELL, B.; ROGERS, L.; PHIL, M. et al. Eosinophilic Dermatitis Associated With Trichosporon asahii in a Cockatiel (Nymphicus hollandicus). Journal of Avian Medicine and Surgery, v.19, n.1, p.25-29, 2005.

GOMEZ-LOPEZ, A.; MELLADO, E.; RODRIGUEZ-TUDELA, J. et al. Susceptibility profile of 29 clinical isolates of Rhodotorula spp. and literature review. Journal of Antimicrobial Chemotherapy, v.55, n.3, p.312-316, 2005.

KREMERY, V.; MATEIKA, F.; KUNOVA, A. et al. Hematogeneous Trichosporonosis in cancer patients: report of 12 cases including 5 during prophylaxis with itraconazol. Support Care Cancer, v.7, n.1, p.39-43, 1999.

LARSSON, C.; LARSSON, M.; AMARAL, R. et al. Dermatitis in dogs caused by Malassezia (Pityrosporum) pachydermatis. Ars Veterinária, v.4, n.1, p.63-68, 1988.

MACHADO, M.; APPELT, C.; FERREIRO, L. Dermatófitos e leveduras isolados da pele de cães com dermatopatias diversas. Acta

Scientiae Veterinariae, v.32, n.3, p.225-232, 2004.

MADRID, I.; GOMES, A.; MATTEI, A. et al. Dermatofitose neonatal canina por Microsporum gypseum. Revista Veterinária e Zootecnia, v.19, n.1, p.773-778, 2012.

MELCHERT, A.; MOTTA, Y.; GIUFFRIDA, R. et al. Avaliação citológica e microbiológica do lavado broncoalveolar em cães hígidos.

Semina: Ciências Agrárias, v.29, n.1, p.157164, 2008.

MORETTI, A.; PASQUALI, P.; MENCARONI, G. Relationship between cell counts in bovine milk and the presence of mastitis pathogens (yeasts and bacteria). Journal of Veterinary Medicine, v.45, p.129-132, 1998.

NAKAGAKI, K.; HATA, K.; IWATA, E. et al. Malassezia pachydermatis isolated from a South American sea lion (Otaria byronia) with dermatitis. Journal of Veterinary Medicine Science, v.62, p.901-903, 2000.

NOBRE, M.; MEIRELES, M.; CORDEIRO, J. Importância do felino doméstico na epidemiologia da dermatofitose por Microsporum canis. Revista da Faculdade de Zootecnia, Veterinária e Agronomia, v.7/8, n.1, p.81-84, 2000.

ONG, R.; RAISIS, A.; SWINDELLS, K. Candida albicans peritonitis in a dog. Journal of Veterinary Emergency and Critical Care, v.20, n.1, p.143-147, 2010.

PASQUALOTTO, A.; ANTUNES, A.; SEVERO, L. Candida guilliermondii as the etiology of candidosis. Revista do Instituto de Medicina Tropical de São Paulo, v.48, p.123-127, 2006.

POLLOCK, C.; ROHRBACH, B.; RAMSAY, E. Fungal dermatitis in captive Pinnipeds. Journal of Zoo and Wildlife Medicine, v.31, n.3, p.374-378, 2000.

PRADO, M.; BRILHANTE, R.; CORDEIRO, R. et al. Frequency of yeasts and dermatophytes from healthy and diseased dogs. Journal of Veterinary Diagnostic Investigation, v.20, p.197-202, 2008.

RIDDELL, R.W. Permanent stained mycological preparation obtained by slide culture. Mycologia v.42, p.265-270, 1950.

SHIN, J.; KOOK, H.; SHIN, D. et al. Nosocomial Cluster of Candida lipolytica Fungemia in Pediatric Patients. European Journal of Clinical Microbiology Infection Disease, v.19, p.344-349, 2000.

SPANAMBERG, A.; WÜNDER JR, E.; PEREIRA, D. et al. Diversity of yeasts from bovine mastitis in Southern Brazil. Revista Iberoamericana de Micologia, v.25, p.154-156, 2008.

YURAYART , C.; CHINDAMPORN, A.; SURADHAT, S. et al. Comparative analysis of the frequency, distribution and population sizes of yeasts associated with canine seborrheic dermatitis and healthy skin. Veterinary Microbiology, v.148, n.2-4, p 356-362, 2011.

ZAAS, A.; BOYCE, M.; SCHELL, W. et al. Risk of Fungemia Due to Rhodotorula and Antifungal Susceptibility Testing of Rhodotorula Isolates. Journal of Clinical Microbiology, v.41, n.11, p.5233-5235, 2003.

ZAITZ, C., RUIZ, L., SOUZA, V. Atlas de Micologia Médica: Diagnóstico Laboratorial. Guanabara Koogan, 2ํed., 2004. 